\title{
A (desconhecida) reforma psiquiátrica em municípios aquém de pequeno porte
}

(The (unknown) psychiatric reform in 'smaller than small' localities)

(La (desconocida) reforma psiquiátrica en municipios de pequeño porte)

\section{Maria Lucia Boarini*}

\author{
Cidadezinha cheia de graça \\ Tão pequena que causa dó \\ Com seus burricos a pastar na praça... \\ Sua igrejinha de uma torre só... \\ Lá toda vida pode morar! \\ Cidadezinha... tão pequenina \\ Que toda cabe num só olhar...
}

Mario Quintana. “A Rua dos Cataventos”. 1938.

\begin{abstract}
Resumo
Este artigo é o resultado de um estudo qualitativo-exploratório, cujo objetivo principal foi conhecer a atenção em saúde mental na rede pública de saúde em um município aquém de pequeno porte. Treze famílias de portadores de transtorno mental (em 7 famílias entrevistadas, houve a participação do paciente) e 10 trabalhadores da saúde do único dispositivo de saúde (UBS) existente no município foram entrevistados. Em geral, para a população entrevistada (tanto familiares, quanto trabalhadores), o problema é de ordem hereditária e social. A medicação copiosamente repetida e o isolamento em hospital psiquiátrico são percebidos com naturalidade. Reconhecem, porém, que a permanência em hospital psiquiátrico deixa a pessoa "mais traumatizada". Tal fato aponta a necessidade de outro olhar para os municípios "minúsculos", maior investimento na formação de equipes multiprofissionais comprometidas com a atenção à saúde mental, que privilegia a atenção de base comunitária e efetivo controle social.
\end{abstract}

Palavras-chave: reforma psiquiátrica; atenção à saúde mental; municípios "minúsculos".

Texto recebido em junho/2008 e aprovado para publicação em outubro/2008.

Doutora, mestre e graduada em Psicologia, professora Associada do Departamento de Psicologia e dos Programas de PósGraduação em Historia da Educação e da Psicologia da Universidade Estadual de Maringá - UEM, e-mail: mlboarini@uol. com.br

1 Adotamos esse termo para indicar os municípios que sequer têm o número de habitantes suficiente para ser nomeado de município de pequeno porte, de acordo com os critérios do IBGE, ou seja, com menos de 20.000 habitantes. 


\begin{abstract}
This article is the result of a qualitative-exploratory study, whose main objective was to learn more on the subject of public mental health care at a municipality classified as 'smaller than small'. Thirteen families of patients with mental disorders were interviewed (in seven of those families, the patient took part in the interview), as well as ten health workers from the only existing health care facility (UBS) in town. In general, according to the interviewed subjects (family members and health workers alike), the problem is hereditary and social. Copiously repeated medication and the patient's isolation in psychiatric wards are perceived as normal. The subjects acknowledge, however, that a stint at a psychiatric ward leaves the person 'even more traumatized'. This highlights the need for a closer look at those 'smaller than small' municipalities, as well as greater investment in the qualification of multi-professional teams committed to mental health care initiatives, which favor community-based care and effective social control.
\end{abstract}

Keywords: Psychiatric reform; Mental health care; 'Smaller than small' municipalities.

\title{
Resumen
}

Este artículo es el resultado de un estudio cualitativo - exploratorio cuyo objetivo principal fue conocer la atención de la salud mental en la red pública de salud en un municipio de pequeño porte. Fueron entrevistadas 13 familias de portadores de trastorno mental (en 7 de las 13 familias entrevistadas hubo participación del paciente) y 10 trabajadores de la salud del único dispositivo de salud (UBS) existente en el municipio. En general, para la población entrevistada (tanto familiares, como trabajadores), el problema es de orden hereditaria y social. La medicación copiosamente repetida y el aislamiento en el hospital psiquiátrico son percibidos con naturalidad. Reconocen, sin embrago, que la permanencia en el hospital psiquiátrico deja a la persona "más traumatizada". Tal hecho (apunta) indica la necesidad de que se vea de otra manera a los municipios "minúsculos", mayor inversión en la formación de equipos multiprofesionales comprometidos con la Atención a la Salud Mental, que privilegié la atención de base comunitaria y efectivo control social.

Palabras clave: Reforma Psiquiátrica, Atención a la Salud Mental, municipios "minúsculos".

m dezembro de 2007, comemoramos, na cidade de Bauru, localizada no Estado de São Paulo, os 20 anos do movimento da luta antimanicomial no Brasil. Nesse evento, foi reafirmada a Carta de Bauru², que traduziu o grito de uma população que não aceitava mais a forma perversa de violência

\footnotetext{
Trata-se de um manifesto popular resultante das discussões realizadas no II Congresso dos Trabalhadores de Saúde Mental, realizado em 1987, no município de Bauru-SP.
} 
institucionalizada que representam os manicômios e todas as outras formas de exclusão e discriminação presentes na sociedade. Firmava-se o compromisso da sociedade para com as pessoas portadoras de transtorno mental. De fato, temos bons motivos para tal comemoração. Como significativo acontecimento na luta pelos direitos da pessoa portadora de transtorno mental, em 6 de abril de 2001, foi aprovada a Lei Federal no. 10.216 (Brasil, 2001), em substituição ao Decreto no. 24.559 (Brasil, 1934). Além desse avanço em termos de legislação, em vários estados do Brasil já contamos com legislação específica sobre esse assunto (Brasil, 2002). No Estado do Paraná, por exemplo, temos a Lei Estadual no. 11.189 (Paraná, 1995). Registramos, também, no transcorrer destes 20 anos, uma crescente expansão da rede de atenção de base comunitária, do que podemos citar como exemplo, entre outros equipamentos e benefícios, a expansão dos centros de atenção psicossocial (Caps), das residências terapêuticas e o Programa Volta para Casa (Brasil/MS/DAPES, 2007). Grosso modo, essas são algumas das razões que justificaram o encontro comemorativo dos 20 anos da luta por "uma sociedade sem manicômios", destacando-se, nesse processo, o protagonismo dos usuários e familiares na transformação desse modelo excludente de atenção à saúde mental.

A literatura especializada, por sua vez, indica várias experiências bemsucedidas, feitas no Brasil, de substituição dos manicômios por uma rede de atenção psicossocial de caráter comunitário. Abordando experiências significativas realizadas nos municípios de São Paulo, Campinas e Santos; temos, por exemplo, os estudos de Maria Claudia Tedeschi Vieira, Maria Cristina Gonçalves Vicentin, Maria Inês Assumpção Fernandes (orgs.) (1999); Florianita Coelho Braga Campos (2000) e Mirna Yamazato Koda (2002). Como ilustração, ainda, temos o estudo de Luzio (2003), que analisou dois municípios de médio e pequeno portes (cidades com 90 e 29 mil habitantes, respectivamente). Em geral, esses estudos, bem como tantos outros sobre o mesmo tema, indicam que os resultados positivos alcançados no movimento de substituição do modelo asilar para uma rede extra-hospitalar de atenção à pessoa com transtorno mental não aconteceram sem o enfrentamento de dificuldades. Pelo contrário, esses estudos indicam resistências significativas na história dessas experiências, provocando, na sequência, em alguns casos, desvio de rota, como foi o caso da implantação do PAS $^{3}$ no município de São Paulo. Assim, o tempo transcorrido deixa claro que, embora essas experiências possam ser consideradas bem-sucedidas em sua implantação, isso não aconteceu sem embates,

\footnotetext{
Em 1993, o governo municipal de São Paulo implantou o Plano de Assistência a Saúde - PAS. Isso significou que a assistência municipal de saúde passou a ser organizada em forma de cooperativas e assumidas pelos funcionários. Dessa forma, nesse período e nesse município, terceirizou-se a assistência à saúde, o que se coloca frontalmente contra as diretrizes e princípios do SUS.
} 
e, na sequência, o seu funcionamento apresentou (ou apresenta) dificuldades para atingir o nível ideal preconizado pela reforma psiquiátrica, motivo de tanta luta.

Outrossim, os avanços realizados não ocorrem de maneira uniforme em todo o território Brasileiro nem se caracterizam como uma ideia hegemônica defendida por todos os segmentos da sociedade do Brasil. Essa questão é evidenciada nas conferências de saúde mental já realizadas, das três esferas governamentais (nacional, estadual, municipal), entre outros fóruns de discussão; e vozes divergentes ainda se fazem ouvir de maneira contundente (França, 2008). Esse fato não deve provocar surpresa, visto que se trata de uma mudança de paradigma e, historicamente, processos dessa natureza não são róseos.

Em que pese a isso, não podemos desconsiderar que ainda temos, no Brasil, 39567 leitos ativos, distribuídos em 226 hospitais psiquiátricos (Brasil/MS/SAS, 2007), o que significa que a luta antimanicomial não terminou.

Diante dessas informaçóes e do fato de que, em geral, os estudos realizados e publicados referem-se a municípios de médio e grande porte, há que se indagar sobre a rede pública de atenção em saúde mental em municípios "minúsculos", cujas características estão aquém de pequeno porte e distantes dos recursos dos grandes centros. Existe um serviço de atenção à saúde mental nesses municípios? Se não há, pelo menos existem planos de implantação? Quais as informações que familiares desses pacientes e profissionais da saúde detêm sobre as diretrizes e princípios da reforma psiquiátrica? Como os familiares desses pacientes e profissionais da saúde moradores desses municípios explicam o transtorno mental e quais as soluçóes que eles buscam para resolver os problemas advindos quando o portador de transtorno mental está em crise? A busca de respostas a essas questōes serviu de estímulo para o desenvolvimento deste estudo, cujo desenho metodológico e resultados apresentamos a seguir.

\section{Método}

Trata-se de uma pesquisa de caráter qualitativo, o que significa, entre outras características, não privilegiar parâmetros de caráter probabilístico, embora estes não possam ser desconsiderados, visto não existir contraposição entre quantidade e qualidade (Frigotto, 1994). Fizemos essa opção por entender que o indivíduo, não obstante suas particularidades, é o ator e produtor da história. Como nos coloca Engels (s/d, p. 285):

A história faz-se de tal modo que o resultado final decorre sempre dos conflitos que se estabelecem entre muitas vontades individuais, cada uma das quais é o resultado de uma multidão 
de condições de existência particulares. E, pois, de um conjunto inumerável de forças que se entrecruzam de um grupo infinito de paralelogramos de forças que dão em consequência uma resultante - o acontecimento histórico.

Sob essa perspectiva, o número de participantes deste estudo não representa uma amostra no sentido estatístico. Esse número foi determinado por aspectos hipoteticamente estratégicos para contribuir nas reflexôes sobre o tema em questão. Tais aspectos, traduzidos em critérios, serão expostos a seguir.

\section{Local da pesquisa}

A pesquisa realizou-se em um município situado no Estado do Paraná, a $570 \mathrm{~km}$ da capital, com área territorial de $237 \mathrm{~km} 2$ e 4147 habitantes. Adotamos o termo minúsculo para adjetivar o município em estudo, por entender que esse termo pode favorecer a ideia de que estamos referindo-nos a uma cidade com o número de habitantes insuficiente para ser considerado um município pequeno, de acordo com o critério do IBGE, já mencionado anteriormente. Além disso, essa cidade está localizada distante da capital e de grandes centros urbanos. A maioria dessa população reside no meio rural (ou "espalhado", como se diz na região) e conta com um ônibus da Prefeitura local, duas vezes por semana, para vir à cidade em busca de atendimento médico e odontológico. Optamos pelo anonimato do município, pois entendemos que os fenômenos destacados neste estudo não são exclusividade dele. $\mathrm{O}$ anonimato, nesse caso, tem a função de possibilitar generalizações. Detalhe que merece destaque e, de certa forma, justifica a generalização, é o fato de que, no Estado do Paraná, existem 399 municípios, dos quais $80 \%$ não ultrapassam o número de 5000 habitantes.

\section{A rede municipal de saúde}

No município em estudo, existe um consultório de odontologia privado e a rede pública de saúde, que conta apenas com uma Unidade Básica de Saúde (UBS), com duas equipes do Programa Saúde da Família (PSF). Cada equipe do PSF é formada pelos seguintes profissionais: 1 médico, 1 enfermeira, 1 dentista, 1 auxiliar de dentista e 6 agentes comunitárias de saúde. Durante a nossa pesquisa de campo, foi admitida uma psicóloga para cumprir 20 horas semanais. Trata-se de uma profissional recém-formada e sem experiência na área da saúde mental ${ }^{4}$. Esses são os únicos profissionais da saúde nesse

4 Na elaboração deste texto, recebemos a informação de que a psicóloga pediu transferência para outro setor e, no lugar dela, foi admitido um outro psicólogo, também recém-formado, para cumprir a mesma carga horária (20 horas semanais). 
município. Quando acometido de surto, o portador de transtorno mental é encaminhado a um dos dois hospitais psiquiátricos existentes em dois outros municípios que fazem parte daquela Regional de Saúde. Esse município não conta, nem mesmo na região, com Centro de Apoio Psicossocial (Caps) ou apoio matricial ${ }^{5}$ da saúde mental.

\section{Participantes}

A ideia inicial era entrevistar apenas os familiares do portador de transtorno mental e os profissionais da Unidade Básica de Saúde do município. Entretanto, nas entrevistas com as famílias, não colocamos objeção quanto à participação do membro da família portador de transtorno mental, se acaso estivesse presente e disponível para tanto. Nessa situação, essa pessoa era convidada a participar da entrevista possibilitando, dessa forma, a manifestação dela. Por essa razão, apesar de não constar do plano da pesquisa, tivemos a participação de sete pacientes durante a entrevista com suas respectivas famílias.

a) familiares: a seleção dos familiares deu-se a partir de uma lista de 148 pessoas moradoras do município e que tomam remédio controlado, cadastradas na Unidade Básica de Saúde. Devidamente autorizadas pelo gestor, entrevistamos $10 \%$ dessas famílias. O critério para compor esses $10 \%$ era: a pessoa cuja família seria entrevistada deveria ter o diagnóstico de transtorno mental e ser egresso de hospital psiquiátrico. Outro critério adotado se relacionava ao motivo da internação, que não poderia ter sido feita por uso de drogas ilícitas ou abuso do álcool. A partir desses critérios, selecionamos aleatoriamente para as entrevistas 13 famílias em que vivem pessoas com transtorno mental. É necessário esclarecer que temos dois irmãos entre os 14 pacientes selecionados para este estudo, o que explica apenas 13 famílias entrevistadas. As características pessoais dos portadores de transtorno mental selecionados para este estudo são as seguintes: a) 6 pessoas do sexo masculino, com idade variando entre 23 e 58 anos; b) 8 pessoas do sexo feminino, com idade variando entre 35 e 50 anos; c) um dos portadores de transtorno mental participante deste estudo tem o ensino médio incompleto; e os demais, o ensino fundamental incompleto; d) em relação à renda, em geral, tanto os familiares quanto os pacientes sobrevivem com salários na faixa do salário-mínimo ou próxima a ele, em geral provenientes do trabalho na agricultura ou de aposentaria; e) quanto ao número de internações, 1 das

\footnotetext{
Apoio matricial é um arranjo organizacional que visa a outorgar suporte técnico em áreas específicas às equipes responsáveis pelo desenvolvimento de açōes básicas de saúde para a população. Esse compartilhamento se produz em forma de corresponsabilização pelos casos, que pode se efetivar por discussōes conjuntas de caso, intervenções conjuntas nas famílias e comunidades ou em atendimentos conjuntos.
} 
pessoas foi internada uma vez, 3 pessoas já estiveram internadas mais de uma vez e 10 pessoas já estiveram internadas mais de duas vezes; d) quanto ao uso de medicação: todos indistintamente, há vários anos, fazem uso de várias associações de medicação controlada, sendo que 9 desses portadores de transtorno mental usam antipsicóticos associados com outros psicotrópicos. Os demais fazem uso de várias outras combinaçôes, tais como ansiolíticos, antiepiléticos, antidepressivos, antiparkinsoniano e estabilizantes de humor.

b) Profissionais da saúde: participaram deste estudo 10 profissionais da saúde, distribuídos da seguinte forma: 2 médicos (=100\%), 1 enfermeira $(1=50 \%$ do total), 1 auxiliar de enfermagem $(1=100 \%), 1$ farmacêutico $(1=100 \%), 1$ auxiliar de farmácia $(1=100 \%), 1$ psicóloga $(1=100 \%)$ e 3 agentes comunitários $(3=50 \%)$. O critério adotado para essa participação foi o de a pessoa ter disponibilidade de tempo para ser entrevistada e vínculo empregatício com a rede básica do município.

\section{Técnica e procedimentos}

Adotamos como técnica a entrevista com roteiro previamente estabelecido de acordo com os objetivos deste estudo. Optamos por essa abordagem por entender que a entrevista pode oferecer "Informações sintomáticas complexas, se não contraditórias, sobre uma sociedade num momento dado de seu desenvolvimento histórico" (Michelat 1981, p. 208). Ainda, de acordo com esse autor:

A partir do discurso das pessoas interrogadas que exprime a relação delas com o objeto social do qual lhes pedem que fale, nosso objetivo é passar pelo que há de mais psicológico, de mais individual, de mais afetivo, para atingir o que é sociológico, o que é cultural (e histórico) (grifo nosso).

Todas as entrevistas realizadas foram gravadas com a aprovação dos participantes e após a leitura e a explanação do termo de consentimento. Posteriormente as gravações foram transcritas na íntegra e submetidas a recorrentes leituras até se alcançar uma "espécie de impregnação". Nesse processo de "impregnação", vão abrindo-se possibilidades de análises ou, de acordo com Michelet (1981, p. 208), "vai-se progressivamente adquirindo a capacidade de elaborar um esquema" que, na sequência, pode favorecer a compreensão dos fenômenos investigados. Na construção desse esquema, à luz dos objetivos propostos neste estudo, destacamos três categorias para discussão: a) os recursos disponíveis no município na assistência à saúde mental na rede pública de 
saúde; b) o conhecimento acerca das diretrizes e princípios da reforma psiquiátrica; c) as explicações sobre o transtorno mental. A apresentação dos resultados está em forma de relato, tendo como ilustração trechos das entrevistas realizadas, cujo conteúdo tem proximidade com as três categorias citadas anteriormente. $\mathrm{O}$ autor do depoimento que serve de ilustração é identificado pela categoria a que pertence (familiar, paciente ou profissional da saúde), acompanhada de uma numeração para diferenciá-lo dos demais.

Essa pesquisa foi aprovada pelo Comitê de Ética em Pesquisa com Seres Humanos da Universidade Estadual de Maringá (Parecer n.o 189/2006 UEM).

\section{Resultados}

a) Os recursos de assistência à saúde mental disponíveis no município na rede pública de saúde

\section{Os profissionais da saúde}

Ao ser solicitado a falar sobre os recursos de assistência à saúde mental no município, o médico 1 responde: "Isso nós não cuidamos"; e justifica: "Nós atendemos cerca de 30 pessoas por turno, de manhã e de tarde". Alega dificuldades para fazer o acompanhamento do paciente com transtorno mental. Nutre expectativas em relação à psicóloga recém-admitida, que poderia fazer esse trabalho, o qual demanda mais tempo e deve ser mais organizado na coleta de dados. Fora isso, "Eles são encaminhados para o psiquiatra, depois eles retornam, e a gente só repete os medicamentos", continua o médico 1. Esse encaminhamento ao psiquiatra citado nessa entrevista refere-se a consultas especializadas oferecidas aos municípios carentes de atendimento médico especializado. No caso do município em estudo, há uma cota mensal de 12 consultas com o psiquiatra, oferecidas pelo consórcio intermunicipal da região. $\mathrm{Na}$ indicação de consulta com o médico psiquiatra, o veículo da unidade de saúde transporta o paciente até o município onde o psiquiatra atende.

Essas informações são confirmadas pela enfermeira, que vai além, ao apontar a medicalização como a solução mais fácil encontrada para dar conta da expressiva demanda pela Unidade Básica de Saúde.

$\mathrm{Na}$ verdade, ali são 30 pacientes que o médico tem que atender por período, não tem aquele tempo de sentar e conversar. Por que 
você está chorando? Por isso? Ah! Vou passar um Amytril ${ }^{6}$ para você. É assim que funciona. Então é bem mais fácil olhar por esse lado, medicalizar todo mundo, porque acaba o problema, daí não tem que forçar a cabeça pra encarar a causa (enfermeira).

Os próprios médicos frustram-se com a repetição das receitas médicas e a falta de acompanhamento do paciente, como afirma o médico 2:

Para mim, é muito frustrante só passar uma receita para o paciente tomar mês a mês a medicação, sem mudar a dosagem. O paciente está há cinco anos tomando a mesma medicação, e você vê que ele estaciona num estágio, e nunca vai ter melhora daquele estágio que ele chegou, porque não teve acompanhamento. Aqui tem uma quantidade enorme de pacientes com distúrbios mentais. Eu não sou especialista, então pra ficar aqui dando diagnóstico, fica complicado.

Para a psicóloga recém-contratada a proposta é:

Tentar montar grupos de autoajuda com essas pessoas. Mas a gente tem um pouquinho de dificuldade por causa do espaço. O mais difícil é atrair esse público para cá. A minha intenção é trabalhar a autoestima, tolerância à frustração, habilidades sociais com essas pessoas. Tem os casos de internação que já teve surto que, às vezes, estão um pouquinho mais fora da realidade... tentar trabalhar com eles de uma forma mais lúdica, pra que eles tenham algum... assim... possam tirar dessa doença alguma coisa de bom pra vida deles, ter algum tipo de qualidade de vida, porque eles não têm nenhum tipo de qualidade de vida. Nem um pouco.

Não há dúvida de que o trabalho baseado no modelo de atenção comunitária deve contemplar a valorização do sujeito historicamente desqualificado e excluído do convívio social e do imaginário coletivo; entretanto a ênfase em grupos de autoajuda e autoestima e outros procedimentos do gênero, sem articulação com outras possibilidades e ações coletivas, pode tomar o caráter de psicologismo que, de acordo com as diretrizes da Política Nacional de Saúde Mental, distancia-se do modelo de atenção psicossocial, cuja meta é desconstruir o paradigma pautado na dicotomia mente/corpo. Essa desconstrução também não se realiza com mais vagas no hospital psiquiátrico, como parece ser a demanda do médico 2, embora esse mesmo profissional reconheça a impropriedade das consultas rápidas:

\footnotetext{
${ }^{6}$ Amytril (nome comercial) do princípio ativo: cloridrato de amitriptilina. Indicaçôes: atua como antidepressivo, antineurálgico, auxilia no distúrbio do pânico, dor neurogênica, síndrome de narcolepsia/cataplexia, profilaxia de cefaleia, inclusive enxaqueca. Na enurese noturna, em que a patologia orgânica foi excluída (Melo, 2005).
} 
Não só uma consulta de 15 minutos a cada quatro meses. Precisaria de um acompanhamento maior, ou um internamento que... às vezes, a gente nem consegue o internamento e, quando consegue, é só para tirar do surto, tirar da crise e volta; e, às vezes, nem tirou da crise e já manda de volta, porque as vagas psiquiátricas são pequenas, e tem que ter rotatividade. [...] Esse é um paciente que tem que ser melhor trabalhado - reconhece o médico 2.

A inexistência de recursos disponíveis para atenção à saúde mental é reafirmada por todos os profissionais:

Acho que você já está percebendo que nós não estamos preparados ainda para lidar com a saúde mental aqui. A nossa equipe não está capacitada. E outra, a maioria dos pacientes vem do interior, tem que pegar ônibus cedo, eles acabam abandonando o tratamento. Não tem essa continuidade na casa, e os nossos agentes comunitários não são capacitados, nem é função deles também estar indo atrás, ensinar o paciente a tomar o remédio afirma a enfermeira.

\section{Familiares}

Apesar dessa situação, os familiares e pacientes, em geral, avaliam o atendimento da rede pública de saúde do município como positivo, porque oferece a medicação necessária e o veículo para transportar o paciente para a hospitalização, quando necessária. "Os remédios, a gente não tem condições de comprar, daí a gente consegue ali pelo posto de saúde" (familiar do paciente 2). E ainda, quando insatisfeitos, o motivo é não ter conseguido uma "transferência" que o familiar não sabe exatamente para onde e para a qual o gestor não aponta nenhuma possibilidade, nenhuma outra referência, como podemos observar no depoimento do familiar do paciente 6 :

Cada vez que a gente ia (ao hospital psiquiátrico), ele estava pior. Aí a gente começou a falar com a secretária da Saúde pra tirar ele de lá, transferir, porque a gente não via melhora nele. Aí ela falou que a gente tinha todo o direito de tirar ele, só que eles não podiam fazer mais nada... Aquilo era um desespero pra mim.

Não obstante o "desespero", a reivindicação, nesse caso, é a transferência de hospital psiquiátrico, o que não sai dos limites de um atendimento ritualístico e simplificador, conforme se perde de vista o doente e se prioriza a doença. Com isso, estamos querendo dizer que os cuidados com a saúde, física ou mental, devem ir além da consulta médica, da oferta da medicação, 
transporte do paciente, etc. Não temos dúvida de que esses serviços traduzem conquistas importantes e direitos já garantidos pela legislação, mas não devem ser entendidos como um favor do gestor desse ou de outro município em particular.

Enfim, se não há um serviço "de medicina mental no município", como afirma o médico 2, buscamos saber se há planos de implantação, ali, de um serviço dessa natureza. A considerar o Relatório Final da VII Conferência Municipal de Saúde desse município, realizada em agosto de 2007, consta de ter havido uma oficina que discutiu "A política do Estado na saúde mental" que resultou nas seguintes propostas:

1) Acompanhar regularmente o paciente portador de doença mental com a equipe técnica multiprofissional, e conscientizar a família para os cuidados com o paciente, através de reunióes semanais ou quinzenais com os mesmos, promovendo cursos artesanais, palestras e ajuda com a higiene pessoal; 2) Fazer valer a lei que proíbe a venda de bebidas alcoólicas para menores; 3) Montar protocolo clínico para prescrição e distribuição de medicamentos especiais, com o médico psiquiatra e supervisão do médico do PSF.

Observadas à luz das entrevistas realizadas, essas propostas, por enquanto, ainda não saíram do papel e parece não haver estímulo para tanto, a considerar que tanto os profissionais da saúde quanto os familiares percebem a internação em hospital psiquiátrico como um caminho "natural" de atendimento.

b) $\mathrm{O}$ conhecimento acerca das diretrizes e princípios da reforma psiquiátrica

\section{Profissionais}

Quando questionado sobre a rede substitutiva de atenção à saúde mental na região, o médico 2 responde imediatamente: "Olha, que eu saiba não"; e faz menção à psicóloga recém-contratada: "E agora parece que há uma psicóloga aqui no município, mas isso começou há um mês. Então, esse tipo de serviço que você colocou, eu realmente desconheço". Para a psicóloga, o conhecimento sobre a reforma psiquiátrica se resume nisto:

[...] Eu fiz um curso, não foi bem um curso, é como se fosse uma conferência na semana passada. Foi falado bastante do fechamento dos hospitais, da reforma psiquiátrica que está tendo, da questão de inserir o indivíduo na sociedade, não fechar ele em um hospital, deixar ele lá três, quatro meses, depois ele volta pra sociedade totalmente fora, sem saber o que está acontecendo. 


\section{Familiares}

Os familiares, em geral, desconhecem qualquer ideia sobre a reforma psiquiátrica, porém têm muito claro o mistério e as péssimas lembranças do hospital psiquiátrico. Também desconhecem os procedimentos terapêuticos adotados nessa instituição, mas são da opinião de que o isolamento em hospital psiquiátrico suspende temporariamente os sintomas e deixa a pessoa "mais traumatizada". Além de desconhecimento, os familiares apontam algo de misterioso na internação, conforme afirma a familiar do (paciente 6):

[...] Do outro lado, você não vê nada. Para visitar, eles vêm para o pátio. Mas a gente ficou sabendo cada coisa... Eu nem sei se é bom comentar também perto dele (refere-se ao paciente que estava presente). Porque ele não lembra de nada. Pra vocês terem uma ideia, de tão ruim, de tão mal que ele ficou, ele não lembra nada.

\section{Portadores de transtorno mental}

Não obstante, alguns pacientes, por um mecanismo qualquer, preferem manter essa experiência na vala do esquecimento, o mesmo não aconteceu com outros pacientes:

Lá tem gente de tudo que é tipo. Lá tem gente que dorme uns minutinhos, depois levanta e não dorme mais, arrebenta portão tudo... Tem gente de tudo que é jeito lá. Ah, lá nós ficamos entediadas o dia inteiro, porque o tempo não passa. Eu canso de assistir televisão. Só daí nem de noite eles não deixavam eu dormir, por isso que eu não quis ficar muito tempo. A turma não se comportava... Tem gente que fica até roxo de tanto que eles dão injeção lá (paciente 4).

Lá? Horrível! Teve um dia que tava lá e tentei fugir, eu lembro que eu joguei pedra nos caminhões verdes. Aí eles me colocaram num lugar onde só tem doido desses que faz coisas na roupa, pegam os doidos à força e faz tomar remédio na marra. Comigo não fizeram isso porque eu ia enfiando a mão na enfermeira. Teve um senhor que veio me falar pra eu não ser agressiva, pra ser boazinha, que daí eles iam me tirar de lá. Aí eu fiz o que ele mandou, consegui me controlar, aí veio equipe de médicos pra conversar comigo, e perguntaram se eu não ia mais fazer aquilo, e eu falei que não. Aí eu fui transferida pra outro quarto, e nesse, as enfermeiras eram bem melhores (paciente 5). 
Diante de tais resultados, com exceção de algumas noçôes precárias, é possível afirmar que há um desconhecimento generalizado tanto da população quanto dos profissionais da saúde, inclusive do profissional da saúde mental, sobre os princípios defendidos pela reforma psiquiátrica e das diretrizes da Política Nacional de Saúde Mental. Esse desconhecimento, como corolário, não deixa espaço para nenhuma problematização, seja no campo teóricoconceitual (sobre o processo saúde-doença), seja no campo político-jurídico (legislação existente, a necessidade do controle social) entre outros; não deixa espaço para qualquer atividade intersetorial que possa fazer uso de recursos da comunidade como o centro esportivo, a biblioteca, a escola, etc., que podem favorecer a integração, a organização e participação da comunidade em todos os dispositivos públicos existentes no município. Esse desconhecimento impede que a população reconheça a não priorização da atenção à saúde mental por parte do gestor. Nessa circunstância, não há elementos para estimular reivindicações para implantação e implementação de uma rede que contemple ações em saúde mental segundo as diretrizes da Política Nacional de Atenção à Saúde Mental.

Nesse contexto, não surpreende o apoio ao isolamento em hospital psiquiátrico.

Olha, teoricamente, eu deveria pensar que eu sou contra, mas eu acho que o sistema ainda não está preparado para adequar essa demanda que foi solta. Porque foi solta, não é? Nós não temos um centro de atendimento para atender essas pessoas, então eu acho que é necessário ter hospital psiquiátrico. Porque a família ainda não aprendeu a lidar, e alguns profissionais ainda também não (enfermeira).

Pode-se ponderar que essa falta de atenção para com a saúde mental em municípios "minúsculos" pode, em termos, ser justificada pelo entrave colocado pela Portaria/GM 336 (Brasil, 2002), que só permite a implantação de um Centro de Atenção Psicossocial em municípios a partir de $20 \mathrm{mil}$ habitantes. Todavia, a partir de 22 de maio de 2006, por meio da Portaria GM no 1.097 (Brasil, 2006), foram incluídos parâmetros para ações de saúde mental na atenção básica (entre outros) nas diretrizes para a Programação Pactuada e Integrada da Assistência à Saúde (PPI). Dessa forma, "intensificouse o esforço de garantir o acesso da população, em especial nos pequenos municípios brasileiros, à atenção em saúde mental”.

De fato, podemos entender que essa Portaria é um avanço em termos de legislação e pode favorecer a população de municípios "minúsculos". Contudo 
não podemos perder de vista que a legislação não tem vida própria; que a legislação por si só não transforma o imaginário popular, que traz arraigado, historicamente, o preconceito e a desinformação a respeito do transtorno mental. São dificuldades que, por vezes, extrapolam a função e abrangência das leis. A superação dessas dificuldades não se fará sem que o gestor faça da atenção à saúde mental uma das prioridades do seu governo, sem que a equipe de profissionais da saúde assuma a responsabilidade pelo cuidado da pessoa acometida de sofrimento psíquico. Para tanto é necessário intensificar a capacitação de equipes multiprofissionais; é necessário estimular a organização e a participação da comunidade em atividades intersetoriais, incentivando a indispensável parceria da comunidade na construção de uma rede social de cuidados à pessoa portadora de transtorno mental.

A ausência de tais condiçôes e parcerias nos leva a suspeitar que apenas a criação de um Centro de Atenção Psicossocial (Caps) ou qualquer outro dispositivo de saúde no município não possibilitará mudanças de paradigmas. E aqui cabe lembrar as criticas de Daud Jr. (2000) em relação aos Caps quando implantados de maneira divorciada de ações gerais de saúde: "Sustentada na tese de centro irradiador de práticas substitutivas, não resiste às evidencias de que se trata de serviços especializados ambulatoriais, na sua maioria reprodutora de práticas cronificadoras, segregadas das ações gerais de saúde [...]”. Nessa perspectiva, qualquer dispositivo de saúde deve, necessariamente, ter uma relação mais orgânica com a comunidade em geral e com os demais dispositivos públicos.

\section{c) As explicações sobre a causa do transtorno mental}

\section{Profissionais da saúde}

Entre os agentes comunitários, a explicação pautada no caráter hereditário é, entre outras, a predominante:
É, eu acho que, para considerar um doente mental, a doença tem que nascer com a pessoa. Ela pode ser um doente mental, mas, se fizer o tratamento corretamente, vai ter chance de se recuperar e ser uma pessoa normal. Agora, as pessoas que nascem assim, já não. Vai morrer com o acompanhamento pra não deixar a doença se agravar mais (agente comunitária 1).

Para a profissional da Enfermagem, a explicação não difere completamente: "O transtorno mental é fator genético ou é pela própria condição da vida da pessoa que ela está sujeita no dia a dia e como ela está entendendo a realidade" 
(enfermeira). Para o médico 1, as causas do transtorno mental são geradas em diferentes campos:

\section{a) o neurológico e hereditário:}

São problemas neurológicos de famílias que têm uma tendência de atitude, de comportamento, diferente... que não é ocasional. São pessoas que têm uma forma de encarar a vida diferente. Por exemplo, aquelas pessoas psicóticas: às vezes têm famílias inteiras com esse tipo de diagnóstico. Então vai para o sobrinho, vai para o neto, e aí são encaminhados para especialistas, e eles vão para tratamento especializado.

\section{b) o intelectual:}

O baixo nível intelectual os impede de sair de situações difíceis, às vezes eles vêm desesperados, simulando crises conversivas, de agitação, enfim, uma série de situações. Não são propriamente e nem especificamente psicológicas, são simplesmente emotivas, de afetividade, emotividade.

c) o social: "Outro fator importante é a falta de trabalho. As pessoas têm pouca opção, e aí vai na casa de um, vai na casa de outro, e pepepê... já sai discutindo. Esse é um dos fatores que mais tem aqui”. E o médico 1 conclui: "Eu diria que $70 \%$ dos nossos pacientes, em relação ao aspecto comportamental, é somatização de algum problema em casa. Esse é o nosso panorama aqui no município.” Para a psicóloga, a questão do transtorno mental passa pela intolerância e pela comodidade:

A maioria não tem tolerância e repertório comportamental pra lidar com isso. Acaba virando uma depressão ou qualquer outra coisa que a pessoa chega ao surto, essas coisas assim... Eu percebo que, às vezes, é cômodo você estar doente, é cômodo ter uma depressão. É um pouquinho difícil conscientizar essa pessoa de que ela pode ter uma vida melhor.

\section{Familiares}

As explicações sobre a origem do transtorno mental transitam por diferentes campos, desde a genética, problemas sociais, tal como a falta de emprego, até crenças populares que se confrontam com afirmações da autoridade médica, como afirma um familiar: 
Eu não sei o que é. Se é "dieta quebrada”. Quando ela ficou mais atacada, foi quando ela teve essa última criança, a filha mais nova. Quando ela estava com dois meses, deu esse problema nela. Já o médico falou que é problema de nascença (familiar da paciente $1)$.

As ideias supersticiosas também concorrem com as possibilidades hereditárias: "Sabe pó de guaraná?... Isso tem uma medida certa pra tomar, mas ele tomou duas vezes essa medida. Não sei, porque a irmã dele tem o mesmo problema que ele. Ela também toma remédio controlado" (familiar do paciente 2). A fragilidade do organismo também pode ser uma explicação:

Eu parei na quarta série, mas passei para a quinta e fui trabalhar na casa de uma japonesa. Ela me matriculou na escola, e parei na sexta série. $\mathrm{O}$ meu problema, o doutor explicou que eu não posso trabalhar e estudar ao mesmo tempo, é muito pesado, minha cabeça fica muito carregada (paciente 3).

Interessante observar que, em nenhuma das entrevistas, ocorreram explicações de caráter místico. Se, por um lado, esse fato indica avanços na busca de explicações, quando se abandona o terreno da espiritualidade, tão a gosto da Idade Média, para adentrar no campo das relações humanas. Por outro lado, as explicações sobre as causas do transtorno mental, em geral, continuam se apoiando em questôes fortuitas, como, por exemplo, o consumo de dose inadequada de guaraná. Ate mesmo quando as causas são remetidas ao campo da ciência, esta parece estar descolada das condiçóes reais que a produziram como, por exemplo, a somatização dos sintomas.

\section{Finalizando}

Sem pretender uma analise exaustiva dos dados coletados, a título de conclusão, destacaremos para discussão alguns aspectos os quais não foram selecionados pelo seu caráter de vetor principal, ou não, da situação posta. Temos claro que a situação social aqui discutida não acontece por conta e risco desse ou daquele fator em particular. São questóes que se entrecruzam e desafiam qualquer analise pontual e linear. É apenas um recorte, cuja compreensão exige a apreensão da totalidade da qual faz parte. Com esse cuidado no método de análise, recuperamos o objetivo principal deste estudo, que é a busca do conhecimento sobre a atenção em saúde mental na rede pública de saúde em um município aquém de pequeno porte ou minúsculo, como preferimos denominar.

No município pesquisado, é declarada a inexistência da atenção à saúde mental na perspectiva extra-hospitalar. Mais que isso, é desconhecida. A 
atenção oferecida ao portador de transtorno mental morador desse município e os princípios da reforma psiquiátrica são estranhos entre si. Constatamos que, entre o que ocorre neste município e o que é preconizado pelas diretrizes da Política Nacional de Saúde Mental e as experiências bem sucedidas divulgadas em congressos e periódicos científicos no que se refere à atenção à saúde mental, só há uma semelhança: o transtorno mental. É a loucura repetindo os mesmos sintomas alucinatórios e delirantes que há séculos desafia o saber científico.

\section{A formação profissional}

Com exceção da admissão da psicóloga recém-formada, nesse município nada faz lembrar os princípios da reforma psiquiátrica. E essa lembrança é bastante pálida quando essa psicóloga revela o seu conhecimento nessa área. E, por essa razão, afirma não ter claro o trabalho que deve ser desenvolvido na atenção básica à saúde. Esse desconhecimento não deve provocar surpresa visto que se trata de uma profissional recém-formada. São inúmeros os estudos já realizados e publicados que apontam a falta de diálogo entre os cursos de formação do psicólogo e o Sistema Único de Saúde. Sensível a essa questão, o Conselho Federal de Psicologia promoveu o I Fórum Nacional de Psicologia e Saúde Pública: contribuiçôes técnicas e políticas para avançar o SUS, realizado em Brasília, em 2006. Isso aconteceu precisamente 16 anos após a implantação do Sistema Único de Saúde, ocorrida no Brasil, em 1990. Se esse tempo transcorrido indica o atraso da categoria de psicólogos nessa discussão, aponta também, e principalmente, a ausência de debates sobre políticas públicas de saúde nos cursos de graduação de Psicologia. Como afirma Bernardes (2006, p. 35):

[...] Jamais (ou pouco) a formação em Psicologia orientou-se para políticas públicas. Ao contrário, a formação orientou-se (e ainda se orienta) para produzir um profissional liberal e para estabelecer relações de privatizações com os espaços públicos - vide o que ocorre em grande parte das clínicas-escola nos cursos de Psicologia, em que, além de existirem profissionais que pouco contato ou interesse possuem com as políticas públicas, são isoladas dos cursos e distantes de suas propostas político-pedagógicos.

Entretanto essa carência de formação não é exclusiva do psicólogo. Salvo erro de generalização, a falta de articulação, em geral, entre os cursos de graduação que formam profissionais da saúde e os princípios do Sistema Único de Saúde é uma constatação. E aqui lembramos Lyra (2007) quando discute as dificuldades de "se fixar os profissionais médicos nas equipes de 
saúde da família e de esses mesmos profissionais direcionarem o olhar para uma assistência integral, sem foco de especialidade". Essa autora afirma:

Tais dificuldades têm tido como causa, entre outras, a atual formação médica que está voltada para uma medicina extremamente especializada, cujos ideais são direcionados a alta tecnologia. Assim quando este profissional se depara, muitas vezes, com uma realidade social distante daquela que estudou, sente angústia, frustração e medo de enfrentar um cotidiano extremamente difícil, que exige dele não só outro olhar sobre a assistência em saúde, mas também capacitação para lidar com situações que exigem respostas inexistentes nos manuais das diversas especialidades médicas (Lyra, 2007, p. 59).

Temos atualmente algumas iniciativas, de caráter não universitário, para tentar solucionar essa necessidade não atendida pelos cursos de graduação na área da saúde, entre outras questôes. Citando como exemplos, temos o Humaniza SUS, por iniciativa do Ministério da Saúde, que reconhece a precariedade de formação do profissional de saúde, principalmente "quando também verificamos que o modelo de formação dos profissionais de saúde mantém-se distante do debate e da formulação das políticas públicas de saúde" (Brasil, 2004). Temos ainda o Programa Nacional de Reorientação da Formação Profissional em Saúde (Pró-saúde), criado em 2005 pelo Conselho Nacional de Secretarias Municipais de Saúde, e tem por objetivo "impulsionar as mudanças curriculares na graduação dos profissionais da área de saúde" (Conasems/ Núcleo de Gestão do Trabalho e Educação na Saúde, 2008).

Enquanto isso, nesse município "minúsculo", a atenção à saúde mental continua reduzida ao uso de medicação, que, via de regra, é um conjunto de psicotrópicos que se repete sistematicamente e em número nada desprezível. É o ritual pragmático e simplificador que se repete, a cada encontro, entre o profissional da saúde e o usuário, sem qualquer questionamento de ambas as partes. É o profissional médico que tem como único objetivo do medicamento a correção de "uma pretensa alteração relativa àquilo que consideramos a sanidade" sem tentar avaliar o que de fato está em questão (Rodrigues, 2003). É o racionalismo médico revelando-se com todo vigor. E, quando ocorre o agravo do transtorno mental, a única referência, nessa situação, é a internação do paciente em hospital psiquiátrico em municípios mais próximos. É o encaminhamento "natural", sem questionamento ou reivindicação de um outro tipo de assistência, que a pessoa portadora de sofrimento mental ignora como direito seu. E assim vamos constatando a ausência do controle social, uma das conquistas sociais mais importantes da sociedade brasileira. 


\section{Controle social}

O desconhecimento dos princípios defendidos historicamente pelo movimento da reforma psiquiátrica e das diretrizes da Política Nacional de Saúde Mental, em nosso entender, serve como um dos pilares de sustentação dessa situação de desamparo assistencial vivida pelos portadores de transtorno mental e seus familiares, nesse município. Tudo ocorre na mais completa inversão das conquistas já determinadas pela legislação. Desconhecendo as possibilidades já garantidas no campo legal, os usuários ficam à mercê do interesse do gestor, que nem sempre tem na atenção à saúde mental uma de suas prioridades, como parece ser o caso do município em estudo. Esse desinteresse pela assistência à saúde mental se explicita quando o usuário solicita à secretaria de saúde que tire seu familiar do hospital psiquiátrico porque não está percebendo melhora e a gestora responde que "não podiam fazer mais nada". Essa resposta ao usuário confirma que, embora conste do relatório da Conferência Municipal de Saúde propostas de atenção à saúde mental, na prática, não passa de "letra morta". Dessa forma, configurase a ausência do controle social que contribui para fragilizar reivindicações e obstruir a operação de uma rede de cuidados que, de fato, desenvolva ações mais resolutivas e de maior abrangência social. E o que se constata é a lógica de saúde assistencialista, que reserva ao usuário um papel passivo e descontextualizado.

\section{Olhar diferenciado}

A situação constatada nesse município "minúsculo", que pode ser muito mais comum do que imaginamos, até mesmo em municípios com diferente densidade demográfica, insistimos nessa hipótese, exige, em nosso entender, um olhar mais acolhedor dos profissionais da saúde em relação ao seu objeto de trabalho, que é a saúde física e psíquica do usuário da rede de saúde. Exige o olhar fiscalizador da população local. Exige um olhar diferenciado por parte dos gestores das três esferas governamentais: municipal, estadual e nacional. E aqui não nos referimos apenas ao campo financeiro e organizacional. Aliás, se observada com cuidado, a legislação e as orientações vigentes, de certa forma, já vêm avançando nesse sentido. Exemplo disso é o documento do Ministério da Saúde que orienta a "inclusão das ações de saúde mental na atenção básica” (Brasil, 2004). Nesse documento, a orientação é que municípios com menos de 20 mil habitantes devem trabalhar com a lógica de apoio matricial cuja "responsabilização compartilhada dos casos exclui a lógica do encaminhamento, pois visa aumentar a capacidade resolutiva de problemas de 
saúde pela equipe local” (Brasil, 2004). Pelo visto, orientações do Ministério da Saúde não faltam, mas não se realizam no cotidiano da saúde pública desse município "minúsculo".

Entendemos que, sem esse olhar diferenciado de todos os envolvidos na área da saúde, sem esse olhar que privilegia o trabalho em equipes multiprofissionais comprometidas com a atenção à saúde mental, que privilegia a atenção de base comunitária e tem como meta a autonomia e saúde do usuário, provavelmente os hospitais psiquiátricos ainda terão vida longa, e os profissionais da saúde continuarão frustrados e desamparados. E isso podemos constatar no comentário do médico 2: "Acho que é até legal começar a ter essa discussão pra gente ver se, no futuro, consegue mudar um pouquinho a realidade desses municípios como o nosso, que é pequeno e que fica meio que desamparado nessa situação". Isso significa que a verticalização no setor de saúde que reserva ao profissional a exclusividade do poder no transcorrer do dia a dia e a falta de resultados pode constituir-se também em um galvanizador de frustrações e desamparo para o próprio profissional de saúde.

\section{Enquanto as mudanças não acontecem}

Os próprios usuários portadores de transtorno mental e seus familiares, intuitivamente, ampliam a escuta e priorizam o diálogo e o acolhimento como forma de aliviar o sofrimento psíquico, como se pode depreender na entrevista com a paciente 5:

Para falar a verdade, eu tenho uma amiga que tem o mesmo problema que eu, mas o dela é mais grave, porque ela tem dois filhos deficientes. Aí eu vou lá converso com ela. Ela mora perto do cemitério. A gente conversa os mesmos problemas, e fica tudo no mesmo. O problema dela é quase igual ao meu; aliás, o dela é pior, porque ela ainda tem as duas crianças que não andam e ela tem que levar para APAE. E, de vez em quando, eu vou dar uma mãozinha pra ela.

Parte, também, de um familiar de uma pessoa com transtorno mental a sugestão de encaminhamento: "Acho que as enfermeiras deveriam ir pra casa dos pacientes, levar a medicação, e as famílias acompanhassem o paciente. Acho que deveriam tentar controlar ao invés de internar todo mundo" (familiar do paciente 7). Em outras palavras, trabalhar no sentido de evitar o agravo do transtorno mental. 
De fato, se assim procedermos, provavelmente tenhamos novos e bons motivos para a próxima Comemoração por uma "Sociedade sem Manicômios", na cidade de Bauru.

\section{Agradecimentos}

Agradecemos à Fundação Araucária de Apoio ao Desenvolvimento Científico e Tecnológico do Paraná da Secretaria de Estado da Ciência, Tecnologia e Ensino Superior do Paraná pelo apoio financeiro.

\section{Referências}

Bernardes, J. (2006). Formação generalista em Psicologia e Sistema Único de Saúde. In: Caderno de texto do I Fórum Nacional de Psicologia e Saúde Pública: contribuiçôes técnicas e políticas para avançar o SUS. (pp. 17-40). Brasília: Conselho Federal de Psicologia.

Brasil. Ministério da Saúde (2002). Legislação em saúde mental: 1990-2002. Brasília: Editora do Ministério da Saúde.

Brasil. Ministério da Saúde (2002, fev. 19). Portaria/GM n. 336, de 19 de fevereiro de 2002. Estabelece as características das modalidades de CAPS (CAPS I, II, III, ad II e i II). Diário Oficial da União.

Brasil. Ministério da Saúde. (2004). Humaniza SUS: politica nacional de humanização: a humanização como eixo norteador das práticas de atenção e gestão em todas as instâncias do SUS. Brasília. Recuperado em 5 de setembro, 2008, de http:// bvsms.saúde.gov.br/bvs/publicacoes/humanizasus_2004.pdf.

Brasil. Ministério da Saúde. (2004). Saúde mental e atenção básica: o vínculo e o diálogo necessários: inclusão das ações de saúde mental na atenção básica. Recuperado em 7 de setembro, 2008, de http://portal.saúde.gov.br/portal/arquivos/pdf/diretrizes.pdf.

Brasil. Ministério da Saúde. (2005). Saúde Mental no SUS. Informativo de Saúde Mental, 4(26). Recuperado em 05 de setembro de 2008, de bvsms.saude.gov.br/ bvs/periodicos/ informesaudemental/boletim21.pdf.

Brasil. Ministério da Saúde. (2006, maio 22). Portaria/GM n. 1097, Define que o Processo da Programação Pactuada e Integrada da Assistência em Saúde seja um processo instituído no âmbito do Sistema Único de Saúde. Diário Oficial da Uniāo. 
Brasil. Ministério da Saúde. (2007). Relatório de gestão 2003-2006: saúde mental no SUS, acesso ao tratamento e mudança no modelo de atenção. Brasília: Editora do Ministério da Saúde.

Brasil. Ministério da Saúde. (2008) Saúde mentale atenção básica: o vínculo e o diálogo necessários: inclusão das açôes de saúde mental na atenção básica. Recuperado em $2 \mathrm{de}$ setembro, 2008, de http://portal.saúde.gov.br/portal/arquivos/pdf//diretrizes/pdf.

Brasil. Presidência da República. (1934, jul 03). Decreto n. 24.559, de 03 de julho de 1934. Dispõe sobre a profilaxia mental, a assistência e proteção à pessoa e aos bens dos psicopatas, a fiscalização dos serviços psiquiátricos e dá outras providências. Diário Oficial da Uniāo.

Brasil. Presidência da República. (2001, abr. 06). Lei n. 10.216, de 06 de abril de 2001. Dispõe sobre a proteção e os direitos das pessoas portadoras de transtornos mentais e redireciona o modelo assistencial em saúde mental. Diário Oficial da Uniāo.

Campos, F. C. B. (2000). O modelo da reforma psiquiátrica brasileira e as modelagens de São Paulo, Campinas e Santos. Tese de doutorado. Programa de Pós-Graduação em Saúde Coletiva. Universidade Estadual de Campinas, Campinas.

Conselho Nacional de Secretarias Municipais de Saúde. (2008). Programa Nacional de Reorientação da Formação Profissional em Saúde. Núcleo de Gestão do Trabalho e Educação na Saúde Recuperado em 5 de setembro, 2008, de http://www.conasems.org. br/files/formacao_profissionais_2008. pdf.

Daud Jr., N. (2000). Considerações histórico-conceituais sobre a instituição psiquiátrica no Brasil e a desinstitucionalização do "doente mental". In: M. L. Boarini. (org.). Desafios na atenção à saúde mental. (pp. 31-64). Maringá: Eduem.

Engels, F. (n.d.). Carta de Engels a Bloch. In: K. Marx \& F Engels. Obras escolhidas. v. 3. (pp. 284-286). São Paulo: Alfa-Omega.

França, J. Erro da política de saúde mental. Recuperado em 4 de junho, 2008, http://www.psiquiatriageral.com.br/residencia/erro_politica_saúde_mental. htm.

Frigotto, G. (1994). O enfoque da dialética materialista histórica na pesquisa educacional. In: I. Fazenda. Metodologia da pesquisa educacional. (pp. 6990). São Paulo: Cortez. 
Instituto Brasileiro de Geografia e Estatística (2008). IBGE Cidades @. Recuperado em 20 de fevereiro, 2008, de http://www.ibge.gov.br/cidadesat/ default.php.

Koda, M. Y. (2002). Da negação do manicômio à construção de um modelo substitutivo em saúde mental: o discurso de usuários e trabalhadores de um núcleo de atenção psicossocial. Dissertação de mestrado. Programa de PósGraduação em Psicologia. Universidade de São Paulo, São Paulo.

Luzio, C. A. (2003). A atenção em saúde mental em municípios de pequeno e médio portes: ressonâncias da reforma psiquiátrica. Tese de doutorado. Programa de Pós-Graduação em Saúde Coletiva. Universidade Estadual de Campinas, Campinas.

Lyra, M. A. A. (2007). Desafios da saúde mental na atenção básica. Cadernos IPUB, 24, 57-66.

Melo,J.M. (2005). Dicionário de especialidades farmacêuticas. Recuperado em 7 desetembro, 2008, dehttp://www.jacotei.com.br/mod.php?module=jacotei. comparacao $\&$ prodid $=366239 \&$ catid $=215 \&$ mostra $=$ true .

Michelat, G. (1987) Sobre a utilização da entrevista não diretiva em Sociologia. In: M. Thiollent. Crítica, metodologia, investigação social e enquete operária. (pp. 191-211). São Paulo: Polis.

Paraná. Governo do Estado. (1995, nov. 09). Lei Estadual n. 11.189, de 09 de novembro de 1995. Dispõe sobre as condições para internações em hospitais psiquiátricos e estabelecimentos similares de cuidados com transtornos mentais. Diário Oficial do Estado do Paraná.

Rodrigues, J. T. (2003). A medicação como única resposta: uma miragem do contemporâneo. Psicologia em Estudo, 1, 13-22.

Vieira, M. T., Vicentin, M. C. G. \& Fernandes, M. I. A. (1999). Tecendo a rede: trajetórias da saúde mental em São Paulo. Taubaté: Cabral Editora Universitária. 